\title{
IMPACT OF ENVIRONMENTAL FACTORS ON MALE REPRODUCTIVE HEALTH
}

DOI: 10.36740/WLek202005132

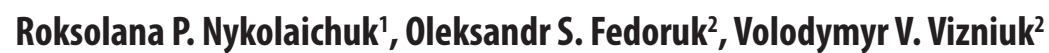 \\ 'PAVOL JOZEF ŠAFARIK UNIVERSITY, KOŠICE, SLOVAKIA \\ ¿HIGHER STATE EDUCATIONAL ESTABLISHMENT OF UKRAINE „BUKOVINIAN STATE MEDICAL UNIVERSITY“ CHERNIVTSI, UKRAINE
}

\begin{abstract}
The aim of our work was to make analysis of world literature that develops a problem of impact of environment on male reproductive health.

Materials and methods: We analyzed the bibliography available, until January 2020, about influence of different exogenic factors on male reproductive system.

Conclusions: The biggest influence of ionizing radiation on mankind was reached after two big catastrophes: Chernobyl Nuclear Power Plant in April 1986 and an accident on the Fukushima Daiichi Nuclear Power Plant in March 2011. However, impact of ionizing radiation on male reproductive in literature still remains controversy that needs more detailed study. Lead influences on such sperm parameters, as sperm morphology, count, motility, semen volume. So, specific attention should be paid to the type of work routinely performed by man. Another one environmental factor that has negative influence is a heat. It effects on sperm morphology and motility.
\end{abstract}

KEY WORDS: infertility, male, environmental exposure, sperm count; radiation, ionizing, metals, heavy

Wiad Lek. 2020;73(5):1011-1015

\section{INTRODUCTION}

Spermatozoa were first described by Leeuwenhoek in 1677 as a tiny „,animalcules “. Unfortunately, for a long time after discovery opinion of scientist about role of spermatozoa was overridden. Just at the beginning of XX-th century sperm count was found to be associated with fertility potential and from that time a variety of sperm tests and semen parameters have been developed.

In the era of ART, which intervenes natural selection, when there is a risk of fertilization of egg by defective father's genetic material, exists an acute need of deep study of parameters of spermiogram as a main indicator of fertility disorders.

\section{THE AIM}

The aim of our work was to make analysis of world latest data that develops a problem of impact of environment on male reproductive system.

\section{MATERIALS AND METHODS}

We analyzed the bibliography available, until January 2020 , about influence of different exogenic factors on male reproductive health that lead to problems of fertilization.

\section{REVIEW AND DISCUSSION}

Infertility is an international problem and involves 15\% of family couples having unprotected sexual intercourse.
Unfortunately, there is no sufficient accurate information indicating the rate of male factor in the whole world $[1,2]$. According to global evidence percentage of male infertility ranges from 20 to $70 \%[1,3,4]$. In general, approximately one third of cases are associated with male reproductive failure. Another third includes female reproductive problems, and the last one - both and other unknown factors of infertility [5].

\section{ENVIRONMENTAL FACTORS INFLUENCING MALE INFERTILITY (EXOGENOUS FACTORS).}

Various ecological factors influencing on male infertility are described in the scientific and medical literature. However, it is the mankind that promoted a negative effect of the environment of the human health due to increase of its own requirements and technological advances producing unfavourable consequences on the surroundings. Thus, air is polluted from different sources (exhaust gases, industrial wastes, burning of wood, coal etc.). These pollutants include $\mathrm{CO}, \mathrm{NO}, \mathrm{SO} \mathrm{i} \mathrm{O}_{3}[6]$. According to the research that took place in Czech Republic it has been conducted dealing with a negative effect of ecological factors on male reproductive function. The research was performed in two groups of people residing in different locations. One group was exposed to severely contaminated environment. Departure from the normal spermiogram parameters was found in men of the group exposed to the effect of polluted air. A negative correlation between the number of spermatozoa in ejaculate and ozone effect was also determined [7] 
Another one study showed that young male residents in areas with high environment exposure had a significantly increased telomere length in sperm. These findings support the view that semen is a sensitive sentinel biomarker of environmental exposure [8].

Several semen parameters (reduced sperm quality and antioxidant defences, altered chemical element pattern), which are associated with residence in a high polluted environment, can be used, as early biomarkers of environmental pollution [9].

\section{HEAVY METALS}

Lead. More than $20 \%$ of the world production and consumption of lead is located in Europe and it is widely used for printing and automobile industry. Sedimentation of lead in the testicles, epididymis, seminal ducts, seminal vesicles and ejaculation itself is toxic for the male reproductive system and inhibits activity of living spermatozoa. Decreased motility and increased incidence of teratospermia with higher doses of lead exposure were detected in workers occupationally exposed to lead exhibited moderately high blood lead levels associated with sexual disorders like decreased libido that was followed by an increased frequency of atheno-, hypo- and teratospermia [10].

Intensification of DNA fragmentation in human semen is a dynamic process, and its final level depends, to a great degree, on the concentration of lead in seminal plasma [11].

Cadmium is released from tannery, smelter, battery crushing unit. The action of cadmium is specific at spermatogenic stage. High doses of cadmium chloride exposure caused rapid testicular edema, haemorrhage and necrosis [10].

In case of exposition to different doses of cadmium dead or pathologically changed spermatozoa were found in the seminal fluid. It is associated with the fact that cadmium effects glutathione peroxidase (GSHB-Px) directly or indirectly, which, in its turn, catalyses destruction of $\mathrm{H}_{2} \mathrm{O}_{2}$ and lipid hydroperoxides by means of reduced glutathione that protects lipid membranes against peroxide damage [10]. It was shown that seminal plasma zinc concentrations from infertile patients were significantly lower than those from normal controls [12].

Chromium. The nephro- and dermatotoxic heavy metal chromium is widely used in refractory, pigment and stainless-steel factory, tannery, welding, engraving and photo processing units. Workers exposed to chromium effect for a long time demonstrate high levels of it both in the blood and in seminal fluid [13]. According to the experimental data of certain authors different doses of chromium, i.e., 20, $40,60 \mathrm{mg} / \mathrm{kg}$ sodium chromate in rats caused narrowing of tubular diameter, decrease of the nuclear size of testicular cells and reduction in cell population of spermatogenic cells [14].

Selenium. On the one hand, selenium role in the human organism is rather considerable as it is a part of the antioxidant system (GSHB-Px in particular) and is the most effective protective method against chromium effect. Al- though, according to laboratory studies selenium dioxide $\left(\mathrm{SeO}_{2}\right)$ produces a negative effect of the testicles. In the experiments with $3 \mathrm{SeO}_{2}$ conducted on rats a considerable degeneration of testicles together with Leydig's cells atrophy was found [15].

Mercury has spermato-, steroido- and fetotoxic effect. Unfortunately, it is widely used in refinery, plastic and paints, antiseptic, scientific instruments, photography, fuel combustion and agriculture field. Mercury chloride exhibited structural alteration of the testicular tissue along with biochemical change [16]. Mercury and its compounds influence on hydrolytic enzymes associated with the membrane in rats resulting in an abrupt decrease of these enzymes, and as a result - progressing degeneration of the peritubular membranes. The degree of damage is in direct proportion to the dose exposed [10].

Arsenic effect on the reproductive system was first studied in mice and fish. According to certain data [17]. In experimental rats it stipulated disorders of spermatogenesis which was associated with dysfunction of the steroid production.

Arsenic effects the process of meiosis and post-meiotic phase of spermatogenesis. Acute arsenic effect causes quick and diffuse disorders of spermatogenesis in mice. Due to the lack of investigations, concerning arsenic effect on the male reproductive system a specific mechanism of its effect is not likely to be proved [17].

Pesticides and other chemicals. A wide range of chemical substances and pesticides are used nowadays. Certain substances disturb the endocrine balance in the body influencing on the reproductive health and resulting in male and female infertility [18].

A study published in Israel involved workers being in contact with pesticides, 1,2-dibromine-3-chlorpropane (DBCP). The data obtained were indicative of the fact that DBCP produces an inhibiting effect on human spermatogenesis [19]. Relying on the data obtained from the experimental group exposed to DBCP impact, the agent was found to lead to irreversible azoospermia. Testicular function was examined in 15 factory workers exposed to DBCP. A quantitative improvement of sperm after interruption of the exposition was observed 36-45 months later in a third of men with azoospermia and a half of men with oligospermia. In addition, the level of gonadotropins increased, and the level of testosterone decreased [20]. At the same time Dauoud and collegues indicated that after exposure to pesticides it was associated with a significantly higher risk of asthenozoospermia and necrozoospermia [21].

A group of researchers examined reduced number of in vitro fertilization in family couples where a husband was exposed to pesticide effect including other chemical substances used in agriculture such as ethylene dibromine and carbaryl associated with decreased spermatozoa function and male infertility. The wives of the husbands being in contact with these substances suffered frequent miscarriages [22].

Ionizing radiation (IR). Nowadays, possibility of acute ionizing irradiation declined according to development 
of a number of events aimed to prevent and protect from IR in industry, and also by acquired skills of work with IR sources. However, increasing production of fissile materials, testing of different atomic devices, nuclear accidents, lead to a global pollution of environment by radioactive substances, to action of which is exposed all population of world. In this condition, one of the main problems of humanity becomes a study of chronic and long-term IR on the human organism and reproductive system in particular.

Different kinds of radiation are widely applied for modern medical purposes to treat cancer, examination and diagnostics. Time and dose of various kinds of radiation can produce a long subsequent effect on the human organism. Roentgen and gamma rays produce a fatal effect on germinal and Leydig's cells in the human body. This kind of radiation can result in irreversible damage leading to infertility [23].

IR is a stream of particles or quants of electromagnetic radiation, the passage of which through a substance leads to its ionization (the transformation of neutral atoms into positively and negatively charged ions) with the formation of electric charges of different signs [24].

Sources of ionizing radiation are: natural (cosmic rays; radioactive substances contained in the earth's crust - uranium, thorium, radium, actinium, etc., in the atmosphere, food, water and living organisms ; radon gas (during radon decay, radioactive alpha particles are formed), ecologically-enhanced natural origin (as a result of human and industrial activity, was subjected to concentration or increased availability, resulting in additional radiation (including radiation from the nuclear waste disposal site) and nuclear facilities); industrial [24].

Reproductive gonads are among the most sensitive tissues to ionizing radiation. Influence on the gonads is dose- and time- depended [25]. Long-term exposure to high levels of IR may produce testicular atrophy thereby shutting of spermatogenesis and lower doses can cause just pathology of motility of spermatozoa [26].

Spermatogenesis - a story of life of one cells population, that is tight connected with its surrounding and totally depends of last, and also of external influence. That is why study of IR influence on spermatogenesis is very important as it has tight connection with a problem solving of infertility [27].

At the present time researches are concentrated on studying of tissue components of testes in a condition of development of pathological processes in organ with aim to find out mechanisms, that are responsible for different violations of spermatogenesis and to find the ways how to restore it function. Actuality of studying of influence of IR on gonads is due to their connection with a reproductive process. The impact of ionizing radiation on spermatogenesis was widely investigated in laboratories and there is certain evidence concerning studies conducted on people. In 1970 American scientists carried out the study on prisoners given their voluntary consent to examine the effect of roentgen rays on testicles and spermatogenesis in particular [28]. The results were indicative of the fact that the dose of
0,11 Gy caused decreasing of number of spermatozoa, at that time, 3-5 Gy resulted in irreversible sterility.

After two, the biggest in the world, nuclear disasters in Chornobyl (1986) and Fukushima (2011) for the last few years many researches began to study effect of low-dose IR on sperm parameters. Unfortunately, till this time, data are controversy and need deep study of this problem.

\section{IMPACT OF IR AND HORMONES}

In a research of the endocrine and reproductive sequelae of total body irradiation for haematological malignancy have been studied in 8 men of reproductive age who were treated with $10 \mathrm{~Gy}$ in five fractions or 12 or $13.2 \mathrm{~Gy}$ in six fractions over 3 days. In this group serum testosterone levels were at normal levels, but gonadotrophin levels were elevated in all patients [29]. Gamma radiation has dose-dependent inhibitory effects on basal and $\mathrm{LH} /$ cyclic AMP-stimulated human Leydig cell steroidogenesis [30]. Hormonal analyses of 12 with different forms and stages of chronic radiation dermatitis caused by accidental exposure to beta and gamma irradiation during and after the Chernobyl atomic power plant accident demonstrated low testosterone plasma levels in two patients, an increase of FSH levels in six patients, and a decrease of LH in one patient [31]. Suppression of testosterone and gonadotropins after irradiation was observed in different strains of rats too [32]. In another study of a group of men treated with testicular irradiation for carcinoma in situ in the remaining testis after orchiectomy for unilateral testicular germ cell cancer was shown that irradiation of the testis with a dose level that eradicates spermatogenesis in men causes undetectable levels of inhibin B in serum. At the same time, neither LH nor testosterone showed a significant decrease after radiotherapy [33].

Effect of chemotherapeutical agents. Treatment of cancer produces a negative effect on male fertility. Treatment by means of chemotherapy and radiation therapy provokes a short-term or irreversible gonad dysfunction and produces cytotoxic effect on men. This type of therapeutic treatment has an unfavourable impact on male ability to have a biological child at the reproductive age. Spermatogenic disorders are based on the fact that sperm cell division is very sensitive to lethal action of cytotoxic agents, radiation, and biological mechanism of spermatozoa production remains stable and unchanged after chemotherapy completion. A reduced number of spermatozoa is associated with cytotoxic side effect of chemotherapy or radiation therapy on spermatogenic epithelium. In case the epithelium is preserved the risk of disturbed reproduction occurs due to manifestation of mutagenic effect of the treatment conducted on spermatozoa. Experimental studies on animals are indicative of trans-generation expression of various forms of a negative effect from miscarriages to cancerogenesis due to DNA damage in the male genome. For several years radiation therapy and chemotherapy were considered to produce a negative effect on the embryonic epithelium in the testicles both at the puberty and mature 
age. Men afflicted with cancer develop gradual decrease of spermatozoa function due to ejaculation problems as a result of radiation and chemotherapy $[34,35]$.

Human reproduction is a highly sensitive process, and cancer and chemotherapy produce a negative impact both on male and female fertility. In case of positive fertilization after the diagnosis of cancer was made and chemotherapy performed, there is a certain risk of possible negative consequences on the perinatal development and manifestation of different defects. The disease and its treatment induce genetic defects of the germinal cells in children and are manifested in the form of deformities and chromosomal abnormalities [36].

Heat influences upon the development of reproductive cells and on the reproductive cycle of living things in general. The nature left the scrotum outside the body in order to remain the testicles in cooler surroundings than the body temperature. Descent of testes into the scrotum occurs in boys at birth. Cryptorchism is manifested mainly in the puberty period and adult life resulting in lack of spermatogenesis. The testes in the scrotum should have the temperature approximately $3-4{ }^{\circ} \mathrm{C}$ lower than that of the normal body temperature for normal functioning of spermatogenesis [37]. The testes are located on the bottom of the scrotum that helps their cooling. Two other key points providing testes cooling are availability of grapelike venous network functioning as a heat exchanger and blood cooling [38]. Normal functioning of the plexus is of an important value to maintain testicles cool, since the process of heat exchange may be disturbed under certain conditions, for example, varicocele. Therefore, the factors preventing cooling influence on the function of the testicles increase unfavourable effect on spermatogenesis. An average or physiologically higher temperature of the testicle skin is associated with considerably lower concentration of spermatozoa leading to deterioration of sperm. $1^{\circ} \mathrm{C}$ temperature increase reduces of spermatogenesis to $14 \%$ and the effect of high temperature results in morphological changes in spermatozoa [39]. The number of pathologically changed morphological spermatozoa becomes $30-60 \%$ as much in case of exposition to high temperatures during 6-8 months. The men working as bakers, welders and casters are exposed to high temperatures from the exogenous sources most often. 30 minutes bathing of laboratory animals in hot water $\left(40-42^{\circ} \mathrm{C}\right)$ resulted in deterioration of spermatogenesis and certain induction of apoptosis of the germinal cells with DNA damage [40].

\section{CONCLUSIONS}

A human being is a part of a huge ecological system and they both are in close relations. Due to an advancing technological process, the man more and more upset the equilibrium of the ecological system, and in its turn, it cannot but affect the human health.

In this review we showed the tight connection between problems of fertility possibilities of a man and environmental factors. In routine clinical practice all the professionals involved in the field of andrology should be well familiar with the issues of environmental and toxic factors causing infertility to ensure correct medical tactics provided to family couples requiring it.

There are limited observational human data, usually retrospective epidemiological studies, and more abundant experimental studies in animals and cells that require more detailed study of impact of environment on a male health.

\section{REFERENCES}

1. Mascarenhas M.N., Flaxman S.R., Boerma T., Vanderpoel S, et al. National, regional, and global trends in infertility prevalence since 1990: a systematic analysis of 277 health surveys. PLoS Med. 2012;9(12):e1001356. doi:10.1371/journal.pmed.1001356

2. ASRM AND SREl, 2008. Practice Committee of The American Society for Reproductive Medicine In Collaboration with The Society for Reproductive Endocrinology And Infertility. Optimizing natural fertility. In Fertility and Sterility. 2008; 90 (3): 1-6.

3. Martinez G., Daniels K., Chandra A. Fertility of men and women aged 15-44 years in the United States: National Survey of Family Growth, 2006-2010. In Natl Health Stat Report. 2012; 51: 1-28.

4. Agarwal A., Parekh N., Panner Selvam M.K., et al. Male Oxidative Stress Infertility (MOSI): Proposed Terminology and Clinical Practice Guidelines for Management of Idiopathic Male Infertility. World J Mens Health. 2019;37(3):296-312. doi:10.5534/wjmh.190055

5. CDC, 2017. Infertility FAQs. [online]. Accessed from: https://www.cdc. gov/reproductivehealth/infertility/.

6. Chalupka S., Chalupka A.N. The impact of environmental and occupational exposures on reproductive health. In Journal of Obstetric, Gynecologic, \& Neonatal Nursing, 2010; 39 (1): 84-102.

7. Sokol R.Z., Kraft P., Fowler I.M., et al. Exposure to environmental ozone alters semen quality. Environ Health Perspect. 2006;114(3):360-365. doi:10.1289/ehp.8232

8. Vecoli C., Montano .L, Borghini A., et al. Effects of Highly Polluted Environment on Sperm Telomere Length: A Pilot Study. Int J Mol Sci. 2017;18(8):1703. Published 2017 Aug 4. doi:10.3390/ijms18081703

9. Bergamo P., Volpea M.G., SLorenzetti S., et al. Human semen as an early, sensitive biomarker of highly pollutedliving environment in healthy men: A pilot biomonitoring study ontrace elements in blood and semen and their relationship with spermquality and Redox status. Reprod Toxicol. 2016;66:1-9.

10. Chowdhury A.R. Recent Advances in Heavy Metals Induced Effect on Male Reproductive Function-A Retrospective. In Al Ameen J Med Sci, 2009, 2 (2). ISSN 0974-1143: 37-42.

11. Wdowiak A., Bien A., Iwanowicz-Palus G., et al. Impact of emotional disorders on semen quality in men treated for infertility. Neuro Endocrinol Lett. 2017;1:50-58.

12. Zhao J., Dong X., Hu X., et al. Zinc levels in seminal plasma and their correlation with male infertility: A systematic review and meta-analysis. Sci Rep. 2016;6:22386. Published 2016 Mar 2. doi:10.1038/srep22386

13. Bonde J.P. The risk of male suibfecundity attributable to wielding of metals: studies of semen quality, infertility, adverse pregnancy outcome and childhood malignancy. In J Androl. 1993; 16 (1): 1-29.

14. Chowdhury A.R., Mitra C. Spermatogenic and steroidogenic impairment after chromium treatment in rats. In Ind J Exp Biol. 1995; 33: 480-484.

15. Chowdhury A.R., Bhatt H.V. Effect of selenium dioxide on the testes of rat. In Ind J Physiol Pharmacol, 1983; 27 (3): 237-240.

16. Chowdhury A.R., Vachhrajani K.D. Methylmercury induced effect on seminiferous PTM in rats. In Ind. J Physiol Allied Sci. 1997; 51: 9-15. 
17. Sanghamitra S., Hazra J., Upadhyay S.N., et al. Arsenic induced toxicity on testicular tissue of mice. Indian J Physiol Pharmacol. 2008;52:84-90.

18. Nabi G., Amin M., RaufT., et al. Link between chronic pesticides exposure and reproductive problems in male farmers. Journal of Biology and Life Sciences. 2014; 5: 65-76.

19. Potashnik G., Ben-Aderet N., Israeli R., et al. Suppressive effect of 1,2-dibromo-3-chloropropane on human spermatogenesis. Fertil Steril 1978; 30: 444-447.

20. Potashnik G., Porath A. Dibromochloropropane (DBCP): A 17-year reassessment of testicular function and reproductive performance. In J Occup Envir Med. 1995; 37: 1287-1292.

21. Daoud S., Sellami A., Bouassida M., Kebaili S., Ammar Keskes L., Rebai T., Chakroun Feki N. Routine assessment of occupational exposure and its relation to semen quality in infertile men: A cross-sectional study. Turk. J. Med. Sci. 2017;47:902-907. doi: 10.3906/sag-1605-47.

22. Tielemans E., van Kooij R., te Velde E.R., et al. Pesticide exposure and decreased fertilization rates in vitro. Lancet. 1999;354(9177):484-485.

23. Meeker J.D., Ehrlich S., Toth T.L., et al. Semen quality and sperm DNA damage in relation to urinary bisphenol $A$ among men from an infertility clinic. Reprod Toxicol. 2010;30(4):532-539. doi:10.1016/j. reprotox.2010.07.005

24. United Nations Scientific Committee on the Effects of Atomic Radiation UNSCEARSources and Effects of lonizing Radiation: Report to the General Assembly, with Scientific Annexes (United Nations Scientific Committee on the Effects of Atomic Radiation). New York, 2000.

25. Kesari K.K., Agarwal A., Henkel R. Radiations and male fertility. Reprod Biol Endocrinol. 2018;16(1):118. Published 2018 Dec 9. doi:10.1186/ s12958-018-0431-1

26. Kumar D., Salian S.R., Kalthur G., et al. Association between sperm DNA integrity and seminal plasma antioxidant levels in health workers occupationally exposed to ionizing radiation. Environ Res. 2014;132:297-304. doi: 10.1016/j.envres.2014.04.023.

27. Neto F.T., Bach P.V., Najari B.B., Li P.S., Goldstein M. Spermatogenesis in humans and its affecting factors. Semin. Cell Dev. Biol. 2016;59:10-26. doi: 10.1016/j.semcdb.2016.04.009.

28. Clifton D.K., Bremner W.J. The effect of testicular X-irradiation on spermatogenesis in man. A comparison with the mouse. In J Androl. 1983; 4 (6): 387-92.

29. Littley M.D., Shalet SM, Morgenstern GR, Deakin DP. Endocrine and reproductive dysfunction following fractionated total body irradiation in adults. Q J Med. 1991;78:265-274.

30. Ramadoss S., Sivaraman P.B., Narayanasami M.B., et al. Radiation exposure impairs luteinizing hormone signal transduction and steroidogenesis in cultured human Leydig cells. Toxicol Sci. 2006;91:550-56.

31. Birioukov A., Meurer M., Peter R.U., et al. Male reproductive system in patients exposed to ionizing irradiation in the Chernobyl accident. Arch Androl. 1993;30:99-104.

32. Abuelhija M., Weng C.C., Shetty G., et al. models of post-irradiation recovery of spermatogenesis: interstrain differences. Andrology. 2013;1(2):206-215. doi:10.1111/j.2047-2927.2012.00034.x

33. Petersen P.M., Andersson A.M., Rorth M., et al. Undetectable inhibin B serum levels in men after testicular irradiation. J Clin Endocrinol Metab. 1999;84(1):213-215.
34. Henriette M., Marianne B., Fossa S.D. The effects of cancer and cancer treatments on male reproductive function. In Nat Clin Pract Urol. 2006; 3 (6): 312-322.

35. Morris I.D. Sperm DNA damage and cancer treatment. Int J Androl. 2002;25:255-261.

36. Mitwally M.F. Effect of cancer and cancer treatment on human reproduction. Expert Rev Anticancer Ther. 2007;7(6):811-822.

37. Setchell B.P. Heat and the testis. In J Reprod Fertil. 1998; 114: 179-184.

38. Piner J., Sutherland M., Millar M., et al. Changes in vascular dynamics of the adult rat testis leading to transient accumulation of seminiferous tubule fluid after administration of a novel 5 -hydroxytryptamine (5-HT) agonist. Reprod Toxicol\{Piner, 2002 \#3901\} 2002; 16:141-50.

39. Paul C., Murray A.A., Spears N., Saunders P.T. A single, mild, transient scrotal heat stress causes DNA damage, subfertility and impairs formation of blastocysts in mice. Reproduction. 2008;136:73-84. doi: 10.1530/REP-08-0036.

40. Wang C., McDonald V., Leung A., et al. Effect of increased scrotal temperature on sperm production in normal men. Fertil Steril. 1997;68:334-339.

This work is a fragment of scientific research work of the department of obstetrics and gynaecology UPJS "Impact of environmental factors on parameters of spermiogram of Ukrainian population".

ORCID and contributionship:

Roksolana P. Nykolaichuk - 0000-0001-9203-0343 A,D

Oleksandr S. Fedoruk - 0000-0002-1218-288X ${ }^{E, F}$

Volodymyr V. Vizniuk - 0000-0002-6955-383X ${ }^{B}$

\section{Conflict of interest:}

The Authors declare no conflict of interest

\section{CORRESPONDING AUTHOR Roksolana P. Nykolaichuk \\ Pavol Jozef Šafarik University , Košice, Slovakia \\ tel: +420720221701 \\ e-mail:Roksolana_gulyk@ukr.net}

Received: 24.01 .2020

Accepted: 31.03 .2020 A - Work concept and design, B - Data collection and analysis, C - Responsibility for statistical analysis,
D-Writing the article, E-Critical review, F - Final approval of the article 